\title{
ANALISIS KETERSEDIAAN DATA INDIKATOR SMART CITY KABUPATEN TEGAL
}

\author{
Maria Dolorosa Kusuma Perdani*1, Inasari Widyastuti², Daru Nupikso ${ }^{3}$ \\ ${ }^{1,2,3}$ Balai Pengembangan Sumber Daya Manusia dan Penelitian Komunikasi dan Informatika Yogyakarta \\ Email: 1'mari026@kominfo.go.id, 1inas001@kominfo.go.id,,3daru001@kominfo.go.id \\ *Penulis Korespondensi
}

(Naskah masuk: 08 Januari 2021, diterima untuk diterbitkan: 19 Oktober 2021)

\begin{abstract}
Abstrak
Smart city merupakan suatu konsep tata kelola yang disusun secara cerdas agar mampu menyelesaikan setiap permasalahan yang ada di masyarakat. Beberapa literatur menyebut bahwa pembangunan smart city tidak dapat dilepaskan dari infrastruktur TIK serta ketersediaan data. Ketersedian data ini menjadi salah satu indikator awal yang penting untuk menentukan langkah menuju smart city. Kabupaten Tegal yang masih berada pada tahap "proses memulai" menuju smart city perlu melakukan pengukuran ketersediaan data indikator smart city agar perencanaan program untuk menuju smart city dapat dilakukan secara komprehensif. Tujuan dari penelitian ini adalah untuk menilai ketersediaan data indikator smart city serta relevansinya dengan kebijakan terkait di Kabupaten Tegal. Penelitian ini menggunakan metode kuantitatif dengan teknik purposive sampling dalam pengambilan sampelnya. Pemilihan responden berdasarkan pada kesesuaian antara latar belakang tugas pokok dan fungsi OPD dengan perannya dalam memperkuat dimensi smart city. Pengukuran indikator smart city merujuk pada Model Smart Sustainable City. Hasil penelitian menunjukkan bahwa ketersedian data di Kabupaten Tegal masih tergolong rendah. Data terkait kesehatan untuk mendukung Dimensi Living sudah cukup tersedia, begitu pula data terkait mitigasi bencana. Namun, data pendukung pada dimensi lain seperti pada dimensi Smart Economy serta dimensi Smart Governance masih rendah.
\end{abstract}

Kata kunci: smart city, data indikator, dimensi smart city

\section{ANAL YSIS OF SMART CITY INDICATORS DATA AVAILABILITY IN TEGAL REGENCY}

\begin{abstract}
Smart city is a governance concept that is arranged intelligently to be able to solve every problem in society. Some literature states that the development of smart cities cannot be separated from ICT infrastructure and data availability. The availability of this data becomes one of the important early indicators to determine the steps towards smart city. Tegal Regency which is still in the "starting process" towards smart city needs to measure the availability of smart city indicator data so that program planning to reach smart city can be carried out comprehensively. The purpose of this study is to assess the availability of smart city indicator data and its relevance to related policies in Tegal Regency. This research uses quantitative methods with purposive sampling technique in taking the sample. The selection of respondents is based on the suitability between the background of the main tasks and functions of the OPD with its role in strengthening the dimensions of the smart city Measurement of smart city indicators refers to the Smart Sustainable City Model. The results showed that the availability of data in Tegal Regency was still relatively low. Health related data to support the Living Dimension is sufficiently available, as are data related to disaster mitigation. However, supporting data on other dimensions such as the Smart Economy dimension and the Smart Governance dimension are still low.
\end{abstract}

Keywords: smart city, indicator data, smart city dimension

\section{PENDAHULUAN}

Perkembangan teknologi telah membentuk sebuah tatanan kehidupan masyarakat baru. Tatanan kehidupan berbasis teknologi ini memberikan kemudahan bagi masyarakat, mulai dari aspek pemerintahan, kesehatan, pendidikan, tata kota bahkan hingga aspek transportasi. Pemanfaatan teknologi informasi guna meningkatkan efisiensi layanan yang dapat memberikan kemudahan bagi masyarakat akan mengantarkan pada sebuah tatanan 
kota cerdas (smart city). Melalui konsep smart city, layanan pemerintah akan menjadi lebih cepat serta memberi dampak positif bagi masyarakat. Rasa aman dan nyaman bagi warga, tata kelola kota semakin efektif dan efisien, peningkatan daya saing dan pertumbuhan ekonomi, serta adanya pemerataan penghasilan merupakan tujuan konsep smart city (Teknologi 2016). Hal penting yang perlu dipahami dalam penerapan smart city adalah teknologi bukan satu-satunya faktor yang menjadikan konsep smart city berhasil diterapkan (Nam and Pardo 2011a; Nam and Pardo 2011b), teknologi sebagai enabler. Fokus utama konsep smart city adalah pada bagaimana mengubah proses bisnis dan tata cara pemerintah daerah dalam melayani warganya.

Gerakan Menuju 100 Smart City yang diinisiasi oleh Kementerian Komunikasi dan Informatika telah mencapai target 100 daerah sebagai role model smart city, dengan 20 daerah diantaranya merupakan kota/kabupaten di Provinsi Jawa Tengah (Saputra 2018; Tribunnews.com 2019). Hal ini memicu Pemerintah Provinsi Jawa Tengah untuk bisa menjadikan seluruh kota/kabupaten di Jawa Tengah sebagai smart city. Kabupaten Tegal sebagai salah satu kabupaten yang sudah memanfaatkan TIK dalam pelayanan publik juga telah melakukan upaya-upaya untuk menuju smart city. Langkah awal yang telah dilakukan Pemerintah Kabupaten (Pemkab) Tegal adalah dengan menetapkan Perbup Tegal Nomor 76 Tahun 2017 tentang Masterplan TIK Kabupaten Tegal Tahun 2017-2021 serta Perda Kabupaten Tegal Nomor 2 Tahun 2020 tentang Penyelenggaraan Sistem Pemerintahan Berbasis Elektronik. Selain menetapkan dua kebijakan tersebut, dibentuk juga Dewan TIK Daerah Kabupaten Tegal periode tahun 2018-2023 yang ditetapkan melalui Surat Keputusan Bupati Tegal Nomor 555/1027 Tahun 2018. Di tahun anggaran 2020 ini, Dinas Komunikasi dan Informatika (Diskominfo) Kabupaten Tegal juga telah mengalokasikan sejumlah anggaran untuk mendukung langkah Kabupaten Tegal menuju smart city. Alokasi anggaran tersebut rencananya akan digunakan untuk pembangunan gedung TIK, pengadaan infrastruktur metro ethernet untuk 18 kecamatan, penyusunan masterplan smart city, penyusunan rencana induk, roadmap dan arsitektur SPBE, serta untuk pengembangan sumber daya TIK.

Selain dengan menetapkan kebijakan-kebijakan serta melakukan upaya-upaya diatas, Pemkab Tegal juga perlu memperhatikan kesiapan internal pemerintah dalam memanfaatkan TIK agar tahapan untuk menuju smart city lebih efisien. Salah satu hal yang perlu dilakukan Pemkab Tegal adalah melakukan identifikasi ketersediaan data indikator smart city serta relevansinya dengan kebijakan terkait. Ketersediaan data indikator smart city yang terintegrasi akan memudahkan pemerintah daerah dalam menghasilkan informasi pembangunan yang lebih akurat (Herawati and Djunaedi 2020).
Kolektivitas data akan berjalan secara sistematis dan cepat dengan memanfaatkan teknologi, dimana selanjutnya data yang yang sudah terkumpul dapat diolah dan dianalisis untuk menghasilkan informasi yang akurat dan digunakan sebagai dasar pengambilan keputusan untuk mempermudah pelayanan (Mursalim 2017). Dalam banyak kepentingan, penilaian indikator pada kota-kota yang dibentuk dalam model perangkingan memiliki dampak positif maupun negatif (Giffinger and Gudrun 2010). Dampak positifnya yaitu menarik perhatian kota sehingga menjadi isu regional yang mendorong pada penemuan kembali posisi kota dan perbaikan isu kebijakan wilayah.

Penelitian terkait ketersedian data indikator smart city sudah dilakukan oleh beberapa peneliti dengan mengacu pada model-model pengukuran yang berbeda. Salah satunya adalah penelitian yang dilakukan oleh Herawati \& Djunaedi (2020) yang menggunakan kompilasi dari beberapa model pengukuran smart city readiness untuk mengetahui data apa saja yang dibutuhkan dan sudah tersedia di Pemerintah Kota Surakarta. Pengukuruan indikator smart city ini perlu untuk dilakukan karena dengan pengukuruan ini nantinya dapat diketahui tingkat kekuatan dan kelemahan sektor tata kelola kota/kabupaten sehingga memudahkan identifikasi area mana yang perlu dikritisi atau menetapkan tujuan prioritas serta mengevaluasi perubahan performansi kota pada periode tertentu dan setelah implementasi smart city dijalankan (UNECE and ITU, n.d.).

Penelitian ini bertujuan untuk mengukur ketersedian data indikator smart city serta relevansinya dengan kebijakan terkait di Kabupaten Tegal. Hasil pengukuran ini diharapkan dapat menjadi salah satu acuan bagi Kabupaten Tegal dalam merumuskan strategi untuk mewujudkan smart city.

\section{METODE PENELITIAN}

Penelitian ini merupakan penelitian dengan metode kuantitatif. Pengumpulan data primer dilakukan melalui survei di OPD-OPD terpilih pada bulan Maret 2020. Teknik purposive sampling digunakan dalam pemilihan OPD dimana pengambilan sampel dilakukan secara sengaja sesuai dengan tujuan penelitian ini. OPD yang menjadi responden dipilih berdasarkan kesesuaian antara latar belakang tupoksi OPD dengan perannya dalam memperkuat dimensi smart city.

Tabel 1. OPD Responden Survei

\section{Smart Government}

1. Badan Perencanaan Pembangunan dan Penelitian Pengembangan

2. Dinas Komunikasi dan Informatika

\section{Smart Living}

1. Dinas Kesehatan

2. Dinas Perumahan Rakyat,Kawasan Pemukinan, Tata 


\begin{tabular}{|c|c|}
\hline \multicolumn{2}{|r|}{ Ruang, dan Pertanahan } \\
\hline \multicolumn{2}{|r|}{ Smart Mobility } \\
\hline 1. & Dinas Pekerjaan Umum \\
\hline 2. & Dinas Perhubungan \\
\hline \multicolumn{2}{|r|}{ Smart People } \\
\hline 1. & Dinas Pendidikan dan Kebudayaan \\
\hline 2. & Dinas Pemberdayaan Masyarakat Desa \\
\hline \multicolumn{2}{|r|}{ Smart Enviroment } \\
\hline 1. & Badan Penanggulangan Bencana Daerah \\
\hline 2. & Dinas Lingkungan Hidup \\
\hline \multicolumn{2}{|r|}{ Smart Economy } \\
\hline & $\begin{array}{l}\text { Dinas Perdagangan, Koperasi, Usaha Kecil dan } \\
\text { Menengah }\end{array}$ \\
\hline 2. & Dinas Perindustrian dan Tenaga Kerja \\
\hline
\end{tabular}

Model pengukuran indikator smart city yang digunakan merujuk pada MSSC (BPSDMP Kominfo Yogyakarta 2019). Dari 3 bagian pada MSSC, penulis hanya akan membahas pada bagian identifikasi ketersediaan data indiator smart sustainable. Dalam pengukuran ketersedian indikator ini tidak ada proses penilaian karena tujuannya adalah mengidentifikasi indikator yang masuk dalam MSSC berdasarkan pengalaman di daerah dan regulasi yang berkembang. Tahapan teknik analisis identifikasi ketersediaan data bersifat deskriptif dengan langkah sebagai berikut:

1) mendekomposisi indikator smart city sesuai dengan dimensi, area kerja, indikator, dan sub indikator

2) memberikan penilaian atribut indikator meliputi:

a. ketersediaan data, TERSEDIA (1) dan TIDAK TERSEDIA (0)

b. sumber data, sebagai identifikasi apakah data tersedia di lingkungan pemerintah daerah atau diluar lingkungan pemerintah daerah (pemerintah pusat, BUMN, BUMD, swasta, komunitas)

c. potensi integrasi data

3) Merekapitulasi ketersediaan data pada indikator dan sub indicator

4) Melakukan pembobotan ketersediaan data pada dimensi dan area kerja.

\section{TINJAUAN PUSTAKA}

Menurut Giffinger (2011) kota cerdas adalah cerdas melakukan pembangunan kotanya dengan cara melihat ke depan. Pendekatan pembangunan kota yang melihat ke depan menuju kota cerdas mempertimbangkan isu-isu, seperti kontribusi, ketegasan diri, kemandirian, dan kesadaran. Giffinger dalam IBM (IBM and Government, n.d.) membagi Smart City menjadi enam dimensi, yaitu Smart Economy, Smart Mobility, Sm art Governance, Smart People, Smart Living, dan Smart Environment. Sementara Boyd Cohen (B. Cohen and Munoz 2015) lebih melihat smart city sebagai pendekatan terpadu yang luas untuk meningkatkan efisiensi dari operasi kota, kualitas hidup warga kotanya, dan menumbuhkan ekonomi lokal. Konsep kota cerdas ini memang membicarakan pemanfaatan teknologi modern dalam kehidupan sehari-hari. Smart city digambarkan oleh Suhono dkk (2018) sebagai kota yang memiliki kapabilitas baik untuk mngelola semua sumber daya secara efektif dan efisien sehhingga dapat memecahkan masalah kota dengan solusi yang inovatif dan integratif serta berkelanjutan untuk meingkatkan kualitas hidup masyarakat. Adapun sumber rujukan Kementerian Komunikasi dan Informatika, Citiasa (2016) menguraikan bahwa smart city dibangun untuk mencapai kehidupan masyarakat yang lebih aman, indah, sehat dan makmur dengan memanfaatkan TIK serta inovasi lainnya yang diarahkan untuk perbaikan, mengurangi biaya, dan melibatkan partisipasi.

Model Smart Sustainable City (MSSC) merupakan set instrumen untuk menyusun strategi implementasi smart city secara berkelanjutan yang mengacu pada kondisi saat ini untuk mengatur kematangan dan kondisi masa depan pada prioritas dan tujuan yang hendak dicapai (BPSDMP Kominfo Yogyakarta 2019). MSSC merujuk pada model Giffinger (2007), model Boyd Cohen (2015), model UNECE ITU (n.d.), model Garuda Smart City Framework (GSCF) oleh Supangkat dkk (2018), dan indikator pengukuran index yang merujuk pada Innovation City $^{T M}$ Index 2018 dan Sustainable Development Goals (SDGs). MSSC ini bekerja dalam 3 (tiga) bagian, yaitu:

1) Mengkaji dan menetapkan komponen smart sustainable city. Yang dilakukan pada bagian ini adalah mengidentifikasi tingkat kematangan ditinjau dari komponen smart sustainable city dengan tujuan untuk mengidentifikasi potensi saat ini serta menetapkan strategi dan peluang implementasi secara tepat.

2) Mengkaji tingkat prioritas dimensi smart sustainable city. Pada bagian ini, dilakukan pengkajian tingkat prioritas dimensi smart sustainable city berdasarkan pengalaman praktis pemerintah daerah mengacu pada area kerja dimensi smart city.

3) Mengidentifikasi ketersediaan data indikator smart sustainable city. Indikator smart city merupakan alat untuk mengevaluasi serta menilai tingkat kekuatan dan kelemahan kota/kabupaten secara spesifik (Giffinger and Gudrun 2010; UNECE and ITU, n.d.). Penilaian indikator ini diperlukan untuk mengetahui impak dari solusi teknologi terhadap peningkatan kualitas hidup masyarakat baik secara langsung maupun tidak langsung sebagai solusi permasalahan urban setidaknya dalam jangka pendek (Yudatama, n.d.). 


\section{HASIL DAN PEMBAHASAN}

Dalam rangka penyelenggaraan tata pemerintahan yang baik, Kabupaten Tegal memiliki rencana untuk menuju smart city. Strategi yang efektif dan efisien diperlukan agar perencanaan program ini dapat dilaksan akan dengan baik. Pengukuran kondisi suatu daerah bisa menjadi langkah awal dalam mengidentifikasi faktor internal dan eksternal yang dimiliki suatu daerah untuk merumuskan strategi menuju smart city.

Salah satu tahapan penting untuk melihat dan menentukan langkah menuju terwujudnya smart city adalah melakukan identifikasi data untuk melihat ketersediaan data indikator smart city. Hasil temuan terkait ketersediaan data indikator pada penelitian ini menunjukkan bahwa Kabupaten Tegal memiliki data terkait kesehatan yang sangat menonjol, disusul kemudian dengan data terkait mitigasi bencana. Tabel 2 berikut menyajikan banyaknya data indikator smart city yang tersedia pada masingmasing dimensi dan area kerja smart city di Kabupaten Tegal berdasarkan survei di lapangan.

Tabel 2. Jumlah Ketersediaan Data Indikator Smart City di Kabupaten Tegal

\begin{tabular}{|c|c|c|}
\hline Dimensi & Area Kerja & $\begin{array}{c}\text { Ketersediaan } \\
\text { Data Indikator }\end{array}$ \\
\hline \multirow[t]{4}{*}{ Smart Economy } & $\begin{array}{l}\text { Infrastruktur Ekonomi } \\
\text { dan Perdanganan }\end{array}$ & 2 \\
\hline & Produktivitas & 6 \\
\hline & Citra Ekonomi & 2 \\
\hline & Inovasi & 4 \\
\hline \multirow[t]{3}{*}{ Smart People } & Kreativitas & 2 \\
\hline & Tingkat Pendidikan & 6 \\
\hline & $\begin{array}{l}\text { Infrastruktur } \\
\text { Pendidikan }\end{array}$ & 5 \\
\hline \multirow[t]{3}{*}{ Smart Living } & Keterpaduan Sosial & 6 \\
\hline & Kesehatan & 17 \\
\hline & $\begin{array}{l}\text { Daya Tarik Wisata } \\
\text { Kota }\end{array}$ & 0 \\
\hline \multirow[t]{3}{*}{$\begin{array}{l}\text { Smart } \\
\text { Environment }\end{array}$} & $\begin{array}{l}\text { Manajemen } \\
\text { Lingkungan Hidup }\end{array}$ & 8 \\
\hline & Mitigasi Bencana & 9 \\
\hline & $\begin{array}{l}\text { Rencana Tata Ruang } \\
\text { Wilayah }\end{array}$ & 4 \\
\hline \multirow{4}{*}{$\begin{array}{l}\text { Smart } \\
\text { Governance }\end{array}$} & Partisipasi Masyarakat & 0 \\
\hline & $\begin{array}{l}\text { Transparansi } \\
\text { Pemerintahan }\end{array}$ & 2 \\
\hline & $\begin{array}{l}\text { Layanan } \\
\text { Pemerintahan } \\
\text { Berbasis Online }\end{array}$ & 3 \\
\hline & $\begin{array}{l}\text { Layanan } \\
\text { Pemerintahan }\end{array}$ & 2 \\
\hline \multirow[t]{5}{*}{ Smart Mobility } & Infrastruktur TIK & 1 \\
\hline & $\begin{array}{l}\text { Manajemen } \\
\text { Transportasi }\end{array}$ & 4 \\
\hline & $\begin{array}{l}\text { Layanan Transportasi } \\
\text { Ramah Lingkungan }\end{array}$ & 1 \\
\hline & $\begin{array}{l}\text { Transportasi Publik } \\
\text { Terinstegrasi dan } \\
\text { Inovatif }\end{array}$ & 5 \\
\hline & $\begin{array}{l}\text { Efisiensi Layanan } \\
\text { Jalan }\end{array}$ & 5 \\
\hline
\end{tabular}

Tabel 2 menunjukkan ketersediaan data pada area kerja kesehatan adalah yang tertinggi, yaitu sebanyak 17 data. Area kerja kesehatan termasuk dalam dimensi Smart Living yang terdiri atas indikator-indikator berupa tingkat harapan hidup, kesehatan ibu hamil dan anak, penyakit menahun dan non menahun serta infrastruktur kesehatan. Secara keseluruhan, ketersediaan data indikator smart city Kabupaten Tegal ini masih terbilang rendah. Bahkan dari hasil pengumpulan data di lapangan ditemukan ada 2 area kerja yang tidak kami peroleh datanya, yaitu area kerja "partisipasi masyarakat" yang merupakan area kerja pada dimensi Governance serta area kerja "daya tarik wisata kota" yang merupakan area kerja dimensi Living. Area kerja partisipasi masyarakat menggambarkan persentasi penduduk yang menggunakan hak pilih dalam pilkada/pemilu; komunitas, LSM, dan lembaga sosial yang aktif mendukung program kabupaten/kota, serta tingkat partisipasi masyarakat ikut dalam proses pengambilan kebijakan, sosialisasi program dan atau kegiatan kabupaten/kota. Adapun area kerja daya tarik wisata kota meliputi jumlah penyelenggaraan atraksi wisata/festival, jumlah situs yang dilindungi dan dikelola, jumlah lokasi turistik, jumlah layanan informasi wisata baik tercetak, online, dan mobile, jumlah kunjungan atraksi wisata/festival, jumlah kunjungan museum/situs per tahun, jumlah kunjungan turis/wisatawan per tahun baik lokal maupun global, serta prosentase alokasi anggaran untuk pengelolaan daya tarik wisata.

a. Ketersediaan Data Indikator Pada Dimensi Smart Economy

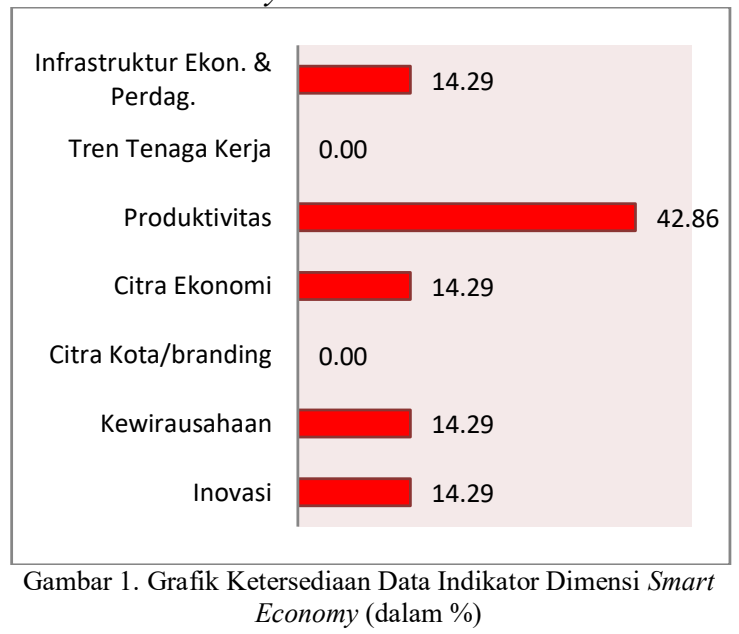

Hasil penelitian menunjukkan bahwa ketersediaan data terkait produktivitas jumlahnya paling banyak. Sebaliknya data terkait tren tenaga kerja dan citra kota atau city branding tidak kami peroleh datanya. Dimensi smart economy ini mempunyai relevansi dengan misi kepala daerah yaitu pada misi nomor tiga "membangun perekonomian rakyat yang kokoh, maju, berkeadilan, dan berkelanjutan", serta program unggulan nomor dua dan enam.

Ketersediaan data yang lengkap dan akurat pada area produktivitas akan menjadi sumber 
informasi dalam menyusun kebijakan maupun program pengembangan sektor UMKM. Pada dasarnya dimensi smart economy menggambarkan dua hal, yaitu inovasi dan daya saing daerah. Keduanya dapat diwujudkan salah satunya dengan menciptakan branding daerah. Membangun perekonomian rakyat yang kokoh dapat diwujudkan dengan menciptakan kepercayaan, baik dari dalam maupun dari luar, dan kepercayaan dapat dibangun melalui citra daerah atau branding. Branding kota yang kuat akan menarik investor dan membangun kepercayaan diri masyarakat dan kalangan UMKM. Branding bukan hanya mengacu pada simbol individu yang mewakili kota, tetapi juga menciptakan gambaran yang lebih luas dan menunjukkan kota secara keseluruhan (Ashworth, Kavaratzis, 2009 dalam Dejanovi 2018). Karenanya sangat disayangkan, ketika data terkait indikator citra kota ini belum kami peroleh datanya.

b. Ketersediaan Data Indikator Pada Dimensi Smart Living

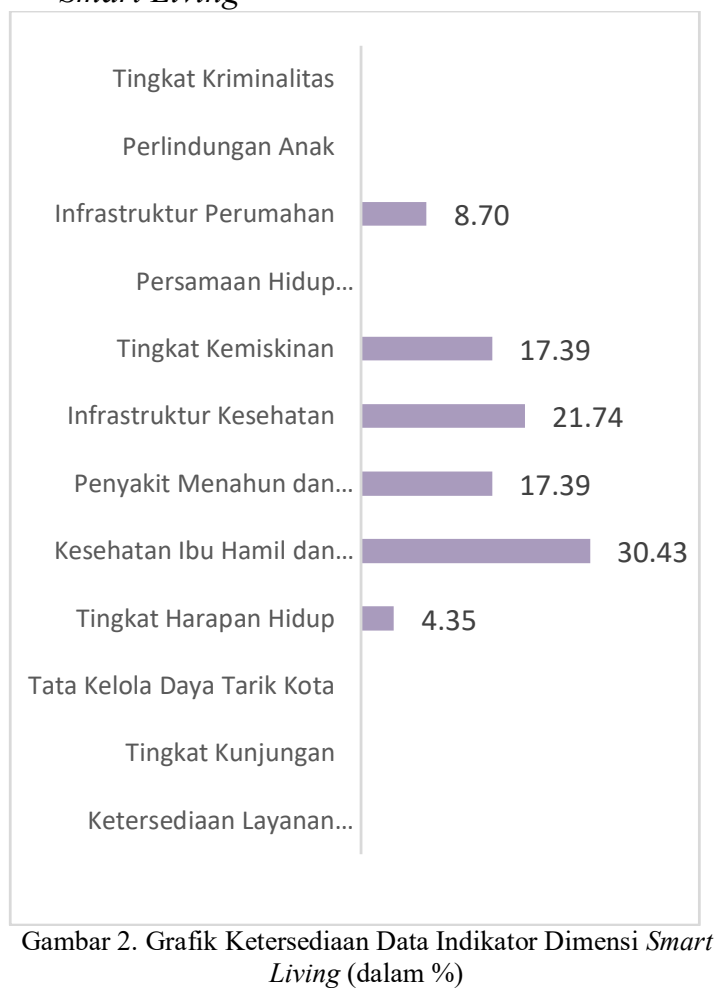

Smart living yang akan diwujudkan dalam smart city menggambarkan proses pengelolaan kualitas hidup. Hal tersebut dapat dicapai melalui aspek budaya, kesehatan dan kehidupan sosial. Ketersediaan data dalam dimensi Smart Living pada dasarnya juga mendukung misi ke empat serta mendukung program unggulan kepala daerah pada butir ke empat dan lima. Hasil penelitian menunjukkan bahwa Kabupaten Tegal kuat pada data kesehatan ibu hamil dan anak serta infrastruktur kesehatan. Namun, data yang terkait dengan indikator-indikator pada area kerja daya tarik wisata serta data indikator tingkat kriminilaitas, perlindungan anak dan persamaan hidup terhadap disabilitas tidak diperoleh oleh peniliti saat pengumpulan data di lapangan. Ada kemungkinan data-data tersebut sebenarnya tersedia, hanya saja data tersebut berada di OPD lain yang tidak terpilih sebagai responden survei.

Pembangunan smart city ditujukan untuk semua warga, tidak terkecuali termasuk disini kaum disabilitas. Data terkait keberadaan dan fasilitas publik yang sudah dan akan disediakan untuk kaum disabilitas menjadi aspek yang penting. Banyak kota yang membangun trotoar sudah mengadopsi fasilitas bagi warga yang mempunyai disabilitas sensori, demikian juga fasilitasi para pengguna kursi roda untuk disabilitas fisik.

Smart living merupakan kondisi kehidupan yang berkualitas termasuk disini budaya yang tumbuh di tengah masyarakat. Untuk mewujudkannya dibutuhkan beberapa syarat, salah satunya adalah tersedianya informasi potensi wisata daerah yang atraktif dengan didukung oleh TIK dan infrastruktur TIK yang memadai sehingga layanan publik dapat diselenggarakan dengan baik.

c. Ketersediaan Data Indikator Pada Dimensi Smart Environment

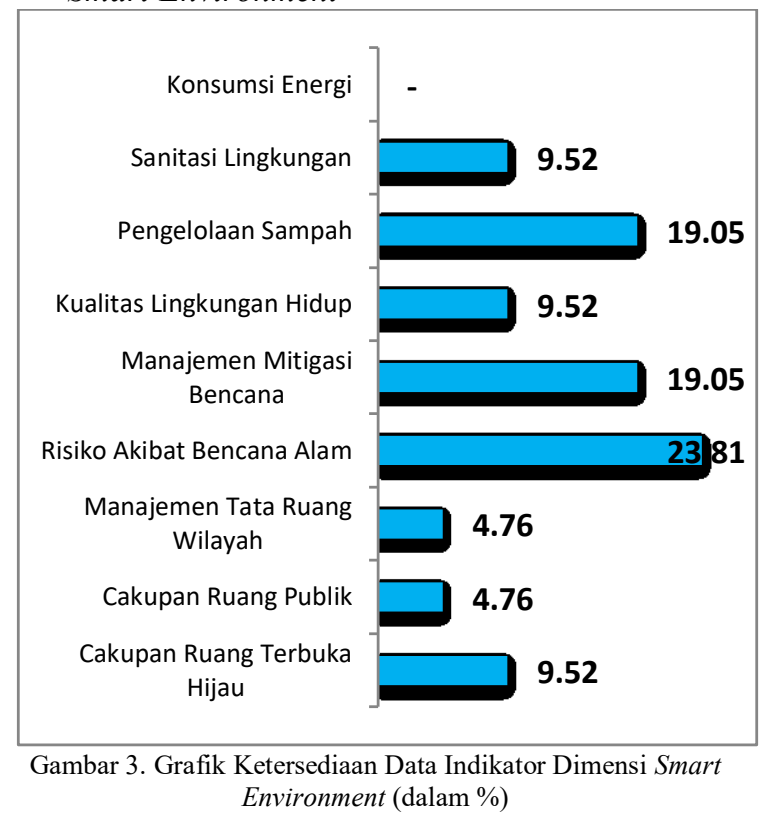

Smart Environment meliputi tata ruang, kebencanaan dan lingkungan hidup yang keseluruhannya akan mewujudkan lingkungan yang memberi rasa nyaman dan aman, menciptakan keindahan baik fisik maupun non fisik serta keberlanjutan. Menurut Gill-Garcia, Pardo \& Nam (eds. 2016) dalam (Rachmawati and Pertiwi 2017), terdapat 10 eleman dalam smart city, dua diantaranya adalah terkait dengan dimensi environment. Kedua elemen tersebut adalah 
membangun lingkungan dan infrastruktur kota, serta melestarikan lingkungan alam dan ekologis.

Pemkab Tegal memiliki data kebencanaan dan manajemen bencana serta pengelolaan sampah yang cukup lengkap, hanya saja belum semuanya disimpan secara digital dan bisa diakses secara online. Ketersediaan data ini dapat mendukung misi ke dua, yaitu memperkuat daya saing melalui pembangunan infrastruktur yang handal, berkualitas, dan terintegrasi serta berwawasan lingkungan.

Agregasi data pada dimensi Smart Environment dapat dilakukan dengan memanfaatkan TIK yaitu dengan melalui sensor yang terpasang. Nantinya dari data yang dihimpun dapat memberikan informasi lingkungan seperti kualitas udara, debit air sungai, pengelolaan limbah dan sampah. Data dan informasi yang diperoleh secara real-time dan akurat akan sangat membantu pemerintah daerah dalam mengambil keputusan sebelum muncul permasalahan atau permasalahan semakin besar. Terkait dengan tata ruang, baik hijau, terbuka maupun pengelolaan tata ruang lainnya, penting untuk mengadopsi sistem teknologi yang menampilkan data geografis atau yang dikenal dengan Geographic Information System atau GIS.

d. Ketersediaan Data Indikator Pada Dimensi Smart Governance

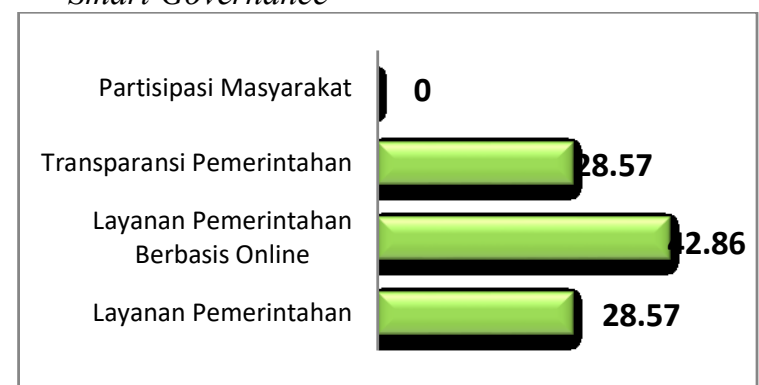

Gambar 4. Grafik Ketersediaan Data Indikator Dimensi Smart Governance (dalam \%)

Beberapa pemerintah daerah membangun smart city dengan mengembangkan konsep $e$ goverment yang sudah ada sebelumnya. Konsep $e$ government sudah digagas pemerintah sejak tahun 2003 dengan dikeluarkannya Instruksi Presiden nomor 3 Tahun 2003 tentang Kebijakan dan Strategi Nasional Pengembangan E-Government. Sejak saat itu pemerintah daerah mulai membangun e-government yang pada awalnya berupa situs web yang kontennya berisi beragam informasi daerah.

Data yang tersedia pada dimensi Smart Governance menunjukkan bahwa Pemkab Tegal unggul dalam data layanan pemerintah berbasis online. Ketersediaan data pada layanan berbasis online di Pemkab Tegal tidak lepas dari praktik layanan pemerintah yang diselenggarakan selama ini. Pemkab Tegal sudah mempunyai beberapa regulasi yang menjadi dasar pemanfaatan dan operasionalisasi TIK. Sejak tahun 2017, melalui Peraturan Bupati nomor 76 Kabupaten Tegal telah mempunyai Masterplan Teknologi Informasi Komunikasi (TIK), disusul dengan terbitnya Peraturan Bupati Nomor 76 tahun 2017 tentang Prosedur Operasional Tata Kelola Teknologi Informasi dan Komunikasi, sesuai amanat Masterplan TIK.

Dukungan layanan berbasis online semakin kuat dengan keluarnya Peraturan Daerah Kabupaten Tegal nomor 2 tahun 2020 tentang Penyelenggaraan Sistem Pemerintahan Berbasis Elektronik. Kedepan, implementasi SPBE terkait dengan data dan informasi akan mendatangkan peluang sekaligus tantangan. Penyelenggaraan SPBE sesuai Perda 2 tahun 2020 tersebut dalam pasal 14 mengatur tentang jenis data informasi yang bersumber atau diperoleh dari dari masyarakat, pelaku usaha, dan/atau pihak lain. Hal ini nantinya akan mengarah pada ketersediaan data yang besar atau big data. Disamping terkait tata kelola, termasuk tantangan dalam melakukan analisis data, faktor standar interoperabilitas data sering menjadi kendala tersendiri. Selain itu, masalah keamanan data yaitu penjaminan kerahasiaan, keutuhan, ketersediaan, keaslian, dan sumber terkait data dan informasi menjadi aspek penting yang harus diperhatikan.

Pada bagian lain, data terkait partisipasi masyarakat tidak tersedia pada saat peneliti melakukan pengumpulan data di lapangan. Area kerja ini merupakan cerminan partisipasi masyarakat maupun elemen yang ada di tengah masyarakat untuk terlibat dalam proses kebijakan pemerintah. Pemkab Tegal sebenarnya telah memiliki aplikasi LAPORBUP dimana aplikasi ini merupakan sarana yang bisa digunakan oleh warga untuk menyampaikan partisipasi mereka dalam rangka pembangunan daerah. Hanya saja, peneliti baru menerima data terkait partisipasi masyarakat yang dihimpun dalam aplikasi LAPORBUP setelah data-data dari pengumpulan data di lapangan selesai diolah dan dianalisa sehingga data yang dihimpun melalui aplikasi LAPORBUP tidak ikut diolah.

\section{e. Ketersediaan Data Indikator Pada Dimensi Smart Mobility}

Hasil temuan penelitian menunjukkan, bahwa ketersediaan data dimensi Smart Mobility didominasi oleh dua indikator yaitu "kualitas dan efisiensi layanan jalan" dan "tingkat kecelakaan lalu lintas". Sebaliknya beberapa indikator tidak diperoleh datanya, yaitu cakupan dan layanan trotoar, lalu lintas kendaraan non-motor, adopsi kendaraan hemat energi, infrastruktur layanan transportasi ramah lingkungan, pantauan lalu lintas, infrastruktur informasi angkutan publik, dan penetrasi infrastruktur TIK. 


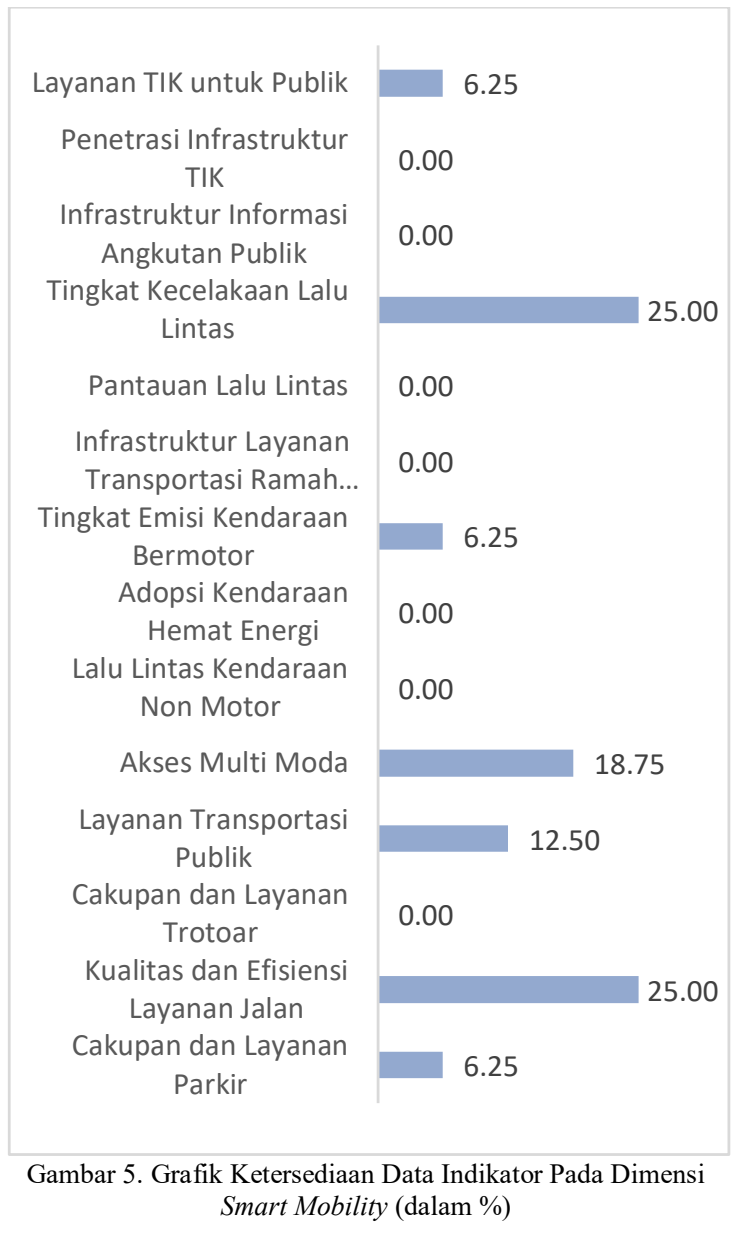

Melalui Smart Mobility, akan tercipta kondisi layanan publik disektor transportasi dan mobilitas yang lebih baik. Permasalahan umum yang sering terjadi dalam moda transportasi seperti kemacetan, pelanggaran lalu lintas, tingginya polusi udara dapat dipantau melalui aplikasi maupun sensor yang dibuat untuk itu. Data yang terkumpul dapat dipergunakan sebagai dasar untuk menemukan solusi serta pengambilan kebijakan.

Mewujudkan Smart Mobility merupakan dukungan nyata bagi misi Kabupaten Tegal, yaitu memperkuat daya saing melalui pembangunan infrastruktur yang handal, berkualitas, dan terintegrasi serta berwawasan lingkungan serta menciptakan tata kehidupan masyarakat yang tertib, aman, tentram, dan nyaman dengan tetap menjaga dan melestarikan nilai-nilai budaya serta kearifan lokal. Adapun terkait dengan program unggulan, smart mobility akan lebih memperkuat jaringan infrastruktur yang akan dibangun Pemkab Tegal.

\section{f. Ketersediaan Data Indikator Pada Dimensi Smart People}

Membangun smart city tidak dapat dilepaskan dari manusia sebagai modal utamanya, karena tujuan smart city secara umum adalah meningkatkan kualitas hidup warga masyarakatnya.

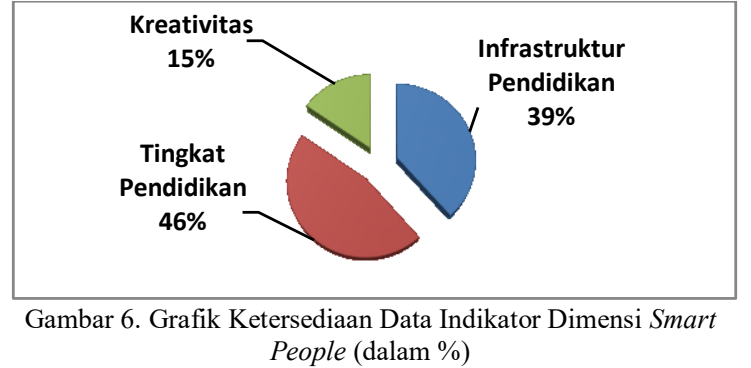

Untuk itu, membangun manusia yang cerdas merupakan modal yang bukan saja untuk manusianya tetapi juga mewujudkan lingkungan sosial yang menjunjung tinggi kemajemukan dan demokratis. Temuan penelitian menunjukkan, ketersediaan data pada dimensi Smart People paling banyak diperoleh pada indikator tingkat pendidikan, disusul dengan infrastruktur pendidikan dan baru kemudian indikator kreativitas.

Ketersediaan data pada dimensi Smart People menunjukkan Pemkab Tegal mempunyai data tentang tingkat pendidikan yang terbanyak (46\%), kemudian infrastruktur pendidikan 39\%, dan kreativitas sebesar $15 \%$. Data pendidikan yang lengkap dan akurat akan sangat membantu Pemkab Tegal dalam menyusun kebijakan dibidang pendidikan.

Membangun manusia cerdas melalui dunia pendidikan dan mendorong kreativitas dapat dilakukan oleh Pemkab Tegal dengan fasilitas yang telah dimiliki, antara lain lembaga pendidikan formal dan ruang kreativitas seperti Tracking Space atau Trasa Co-Working Space yang telah dimiliki Pemkab Tegal. Membangun manusia cerdas selaras dengan misi yang telah dicanangkan, yaitu misi ke empat dan ke lima, serta program unggulan khususnya program ke delapan dan sembilan.

\section{KESIMPULAN}

Kota yang sukses mengimplementasikan smart city adalah kota yang mampu menggunakan data sebagai aset berharga untuk mencapai keluaran atau tujuan strategisnya. Data mampu memberikan wawasan dan pengetahuan baru bagi daerah sehingga dapat mengambil keputusan dan tindakan yang tepat. Dalam konsep smart city, daerah tidak hanya membangun dan menyediakan aplikasi layanan publik, namun daerah juga memiliki kemampuan untuk mengumpulkan, mengungkapkan, serta menggunakan data secara lebih komprehensif untuk proses pengambilan keputusan serta memprediksi tantangan di masa depan.

Ketersedian data menjadi salah satu indikator awal yang penting untuk menentukan langkah menuju smart city. Dari hasil temuan, ketersedian data di Kabupaten Tegal masih tergolong rendah dan belum semuanya disimpan dalam bentuk digital dan online. Data terkait kesehatan untuk mendukung Dimensi Living sudah cukup tersedia, begitu pula data terkait mitigasi bencana. Namun, data 
pendukung pada dimensi lain seperti pada dimensi Smart Economy serta dimensi Smart Governance masih rendah. OPD-OPD terkait perlu didorong untuk dapat menyediakan data-data indikator smart city dengan lengkap serta secara online, sehingga kendala yang mungkin timbul terkait keterbukaan data untuk publik, optimasi data sebagai aset serta implementasi pada berbagi data tingkat lanjut serta analisis data dapat teratasi.

\section{DAFTAR PUSTAKA}

BPSDMP KOMINFO YOGYAKARTA. 2019. "Usulan Model Kota Cerdas Berkelanjutan Yang Integratif: Smart Sustainable City Model." Yogyakarta.

CITIASIA CENTER FOR SMART NATION. 2016. "Smart Nation: Mastering Nation , S Advancement from Smart Readiness to Smart City."

COHEN, B., AND P. MUNOZ. 2015. Toward a Theory of Purpose-Driven Urban Entrepreneurship. Organization \& Environment. $\quad$ Vol. 28. doi: $10.1177 / 1086026615600883$.

COHEN, BOYD. 2015. "The Smartest Cities In The World 2015 : Methodology. Fast Company." http://www.fastcoexist.com/3038818/thesmartest-cities-in-the-world-2015methodology.

DEJANOVI, ALEKSANDAR. 2018. "City Branding as a Potential for Economic Development." In .

GIFFINGER, RUDOLF. 2007. "Smart Cities Ranking of European Medium-Sized Cities" 16 (Octobe: 13-18. doi:https://doi.org/10.1016/S02642751(98)00050-X.

EUROPEAN SMART CITIES. 2011. The Need for a Place Related Understanding Outlook: Smart Metropolitan Development." Science, $1-19$.

GIFFINGER, RUDOLF, AND H. GUDRUN. 2010. "Smart CIties Ranking: An Effective Instrument For The Positioning Of Cities." ACE: Architecture, City, and Environment 4 (12): 7-25.

HERAWATI, MIRAEKI, \& ACHMAD DJUNAEDI. 2020. "Ketersediaan Data Dalam Mendukung Smart City Readiness Di Kota Surakarta." Journal of Regional and Rural Development Planning 4 (1): 63-73. doi:http://dx.doi.org/10.29244/jp2wd.2020.4.1 .63-73.

IBM, \& Solutions Government. n.d. "IBM Smarter City."

MURSALIM, S.W. 2017. "Implementasi Kebijakan Smart City Di Kota Bandung." Jurnal Ilmu
Administrasi 14 (1): 126-38.

NAM, T, \& T. A. PARDO. 2011a. "Conceptualizing Smart City With Dimensions of Technology, People, and Institutions." In Proceedings of the 12th Annual International Digital Government Research Conference on Digital Government Innovation in Challenging Times - Dg.o '11, 282. doi:https://doi.org/10.1145/2037556.2037602.

SMART CITY AS URBAN INNOVATION. $2011 \mathrm{~b}$. Focusing on Management, Policy, and Contex." In ICEGOV'11 Proceedings of the 5th International Conference on Theory and Practice of Electronic Governance, 185-94. doi:https://doi.org/10.1145/2072069.2072100.

RACHMAWATI, TUTIK, \& PRISKA DIAH PERTIWI. 2017. "Smart Environment Program, Smart Way to Smart City." Policy \& Governance Review $1 \quad$ (1): 26. doi:10.30589/pgr.v1i1.24.

SAPUTRA, IMAM YUDA. 2018. "13 Daerah Di Jateng Jadi Role Model Smart City." Solopos.com. https://www.solopos.com/13daerah-di-jateng-jadi-role-model-smart-city915806.

SUPANGKAT, S. H., A. A. ARMAN, R. A. NUGRAHA, \& Y. A. FATIMAH. 2018. "The Implementation of Garuda Smart City Framework for Smart City Readiness Mapping in Indonesia." Journal of Asia-Pacific Studies (Waseda University) 32 (4): 169-76.

TEKNOLOGI, K. R. 2016. Urgensi Penelitian Dan Pengembangan Teknologi Di Bidang Smart City. Kemenristekdikti.

Tribunnews.com. 2019. "Memasuki Tahun Ke-3, Gerakan Menuju 100 Smart City Pilih 25 Kota/Kabupaten Untuk Proses Pendampingan." https://www.tribunnews.com/nasional/2019/05 /15/memasuki-tahun-ke-3-gerakan-menuju100-smart-city-pilih-25-kotakabupaten-untukproses-pendampingan.

UNECE, \& ITU. n.d. "The UNECE-ITU Smart Sustainable Cities Indicators.pdf."

YUDATAMA, UKY. n.d. "Pengukuran Penerapan Teknologi Informasi Untuk Membangun Smart City." In Konferensi Nasional Sistem Informasi (KNSI). 